\title{
Library 2.0 and UK academic libraries: drivers and impacts
}

\section{by Pride Shoniwa \& Hazel Hall}

Corresponding author: Hazel Hall, h.hall@napier.ac.uk

This is a preprint of an article submitted for consideration in the New Review of Information Network 2008. New Review of Information Networking is available at: http://journalsonline.tandf.co.uk

\section{Abstract}

At a time that the term "Library 2.0" has attracted attention in the professional and academic pres library and information science, there appears to be a lack of consensus as to what this nomencla actually means. At one extreme Library 2.0 is purported to be primarily concerned with implementation of web-based tools, and thus supports the view that its drivers are intimately relat $\epsilon$ technology. However, it has also been suggested that Library 2.0 is not solely about technolc Rather, the concept also incorporates changing the physical activities and services delivered libraries, i.e. Library 2.0 is services-driven. Another perspective is that libraries have always he history of adopting technology and user-centred improvements to services, and thus Library 2.0 not even be anything new. This article reports on a research project which assessed the perceptior Library 2.0, and the extent of its adoption, in the UK academic library sector. The main finding of study is that Library 2.0 is predominantly viewed as the selective application of Web 2.0 tools techniques with user services at the heart of any implementation. Although Library 2.0 does not pre a new paradigm, its effects are felt in services delivery. Of particular interest are changes in relationships between those who provide information services and the different generations of the users that they serve. 


\section{Introduction}

The concept of Library 2.0 follows a wider ideology that Web services have evolved from the "st: first generation of the 1990s. It is asserted that this new Web is different because it encour: collaboration and user contribution in a participatory environment. Whilst there has been no ger consensus on this perspective, the term Web 2.0 has since emerged and been accepted to desc this perceived transition of the Web. It mainly describes the principles that are argued to resemble new Web such as the network is the platform, software is a service; users add value and ther continuous reuse of services. ${ }^{1}$ Consequently, the emergence and wide spread use of social sites : as MySpace and YouTube may seem to suggest that the trend is indeed moving towards collabor: and participatory Web services. ${ }^{2,3}$ The success and adoption of tools such as blogs and wikis further propelled the notion of a Web in transition. To this end, the call is that libraries shc acknowledge and embrace this phenomenon by integrating such tools and services into the lib environment. 4

Whilst the discussion of Library 2.0 has gathered momentum, literature in the "biblioblogosph reveals a lack of consensus as to what Library 2.0 seeks to address, that is, the boundaries th covers. For instance Maness ${ }^{6}$ suggest s Library 2.0 to be the "... application of interactive, collabora and multi-media web-based technologies to web-based library services and collections". Library 2 purported to be primarily web-based and hence said to involve the implementation of web $t$ particularly Web 2.0 tools This perspective is one that gives the impression that Library 2.0 is prim technology driven. However, it has further been suggested that Library 2.0 is not all about echnol Casey and Savastinuk ${ }^{7}$ assert that Library 2.0 also incorporates changing the physical activities services delivered by libraries. These are not necessarily web-based activities and services deliv by libraries Here it is argued that Library 2.0 is services driven. That said, it is further argued libraries have always had a history of adopting technology and user-centred improvements to serv hence Library 2.0 may not even be something new. ${ }^{8}$ 
To this end, the research discussed in this paper aimed to draw on the experience of UK acadt librarians who adopted Library 2.0, with the goal of assessing the extent of implementation. It soug address two key research questions as related to UK academic libraries:

- $\quad$ is Library 2.0 primarily concerned with the implementation of Web tools or does it incorpora broader servicesapproach that includes physical services?

- what is the potential impact of Web 2.0 or Library 2.0 on information services provision?

\section{Research Design}

Three main data collection exercises were employed. Firstly, an audit of university library web pagt ascertain the "visibility" of Web 2.0 implementation was conducted in February 2007. The reasor this approach was that it has been asserted that Library 2.0 is the implementation of Web 2.0 systematic navigation of the UK Higher Education and Research library web pages was condu alphabetically using the directory at http://www.library.ex.ac.uk/internet/uklibs.html. It was a simple । of recording visibility of Web 2.0 technologies such as blogs, RSS, podcasts, among others. became data set "A". Subsequently, in March 2007 an invitation to complete a web survey was se all chief librarians of UK HE academic libraries requesting that they either responded themselve nominated a colleague to respond. The response rate for this exercise was $32 \%$ and became dat: "B". Lastly follow-up interviews were conducted with a sample of academic librarians in April $20 \mathrm{C}$ total of six people were interviewed. Four interviews were conducted on-site and two by telephone. became data set " $C$ ". The data sets are summed up in table 1. 


\begin{tabular}{|c|c|c|c|c|}
\hline $\begin{array}{r}\text { Data } \\
\text { Set }\end{array}$ & $\begin{array}{c}\text { Data } \\
\text { Collection } \\
\text { Tool }\end{array}$ & Sample & $\begin{array}{l}\text { Sample } \\
\text { size }\end{array}$ & $\begin{array}{c}\text { Date of } \\
\text { data } \\
\text { collection }\end{array}$ \\
\hline$A$ & $\begin{array}{l}\text { Audit of } \\
\text { library } \\
\text { websites }\end{array}$ & $\begin{array}{l}\text { AIIUK HE libraries as identified from } \\
\text { http://www.library.ex.ac.uk/internet/uklibs.html }\end{array}$ & 152 & Feb 2007 \\
\hline B & $\begin{array}{l}\text { Web- } \\
\text { based } \\
\text { survey }\end{array}$ & $\begin{array}{l}\text { All UK HE chief librarians invited to } \\
\text { participate }\end{array}$ & 152 & $\begin{array}{l}\text { March } \\
2007\end{array}$ \\
\hline$c$ & $\begin{array}{l}\text { Follow-up } \\
\text { interviews }\end{array}$ & $\begin{array}{l}\text { Library staff who were perceived to have } \\
\text { strong interests in Library } 2.0\end{array}$ & 6 & April 2007 \\
\hline
\end{tabular}

Table 1. Data set summary

Research Findings

Is Library 2.0 primarily about the implementation of Web 2.0 tools?

The literature review had established that many asserted that Library 2.0 is primarily the implement: of Web 2.0 tools and the increase of virtual services within the library environment. 4, 5, 6, 8, 9 research set out to test this assertion.

Data collection exercise A was conducted to establish uptake of Web 2.0 technologies by UK acad libraries as of February 2007. A snap shot of uptake is shown in Figure 1. 


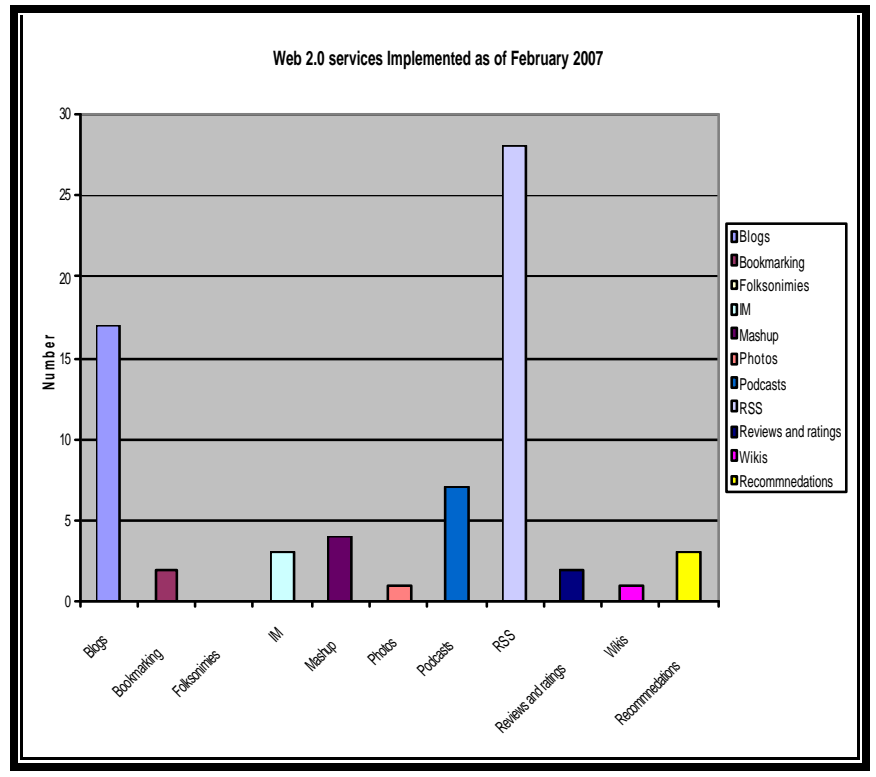

Figure 1. Web 2.0 services implemented as at February 2007

It can be seen that as of February 2007 UK HE libraries were implementing and using some of the ' 2.0 technologies. By far, the most popular tool was the RSS feeds. Of the 152 libraries on the UK directory website, 28 university libraries had RSS already installed. This amounted to $18 \%$ of the s population. This is not particularly high a percentage but for the purposes of answering the rese question, the findings confirmed the presence of Web 2.0 tools. The main use for RSS was to $c$ users the ability to subscribe to the library blog s and also to notify users of any new acquisitions. It therefore not surprising that blogs were the second highest service already implemented since $r$ RSS feeds linked to the library blogs. The blogs were largely used for posting library news and allo users to post comments. In total, 17 universities had implemented blogs, thus amounting to $11 \%$ o study population. Other than podcasts (7 libraries) there was little evidence to suggest wholehea adoption of Web 2.0 tools in the UK academic libraries on the basis of this visibility audit. 
The issue of whether Library 2.0 represents the implementation of Web 2.0 tools in a library setting considered in responses to questions posed in the web-based survey. Specifically, respondents । asked to indicate their level of agreement to the assertion that Library 2.0 is about implementing technologies such as blogs and wikis. A total of 49 responses were received for this question. $63^{\circ}$ the librarians 'agreed' that Library 2.0 was about implementing new technologies. Furthermore, : showed strong agreement. In order to have a consolidated opinion on the level of agreement, scales for 'strongly agree' and 'agree' were aggregated to represent the overall level of agreen Similarly, this was done for the 'strongly disagree' and 'disagree' options on the scale. Conseque the results revealed that $94 \%$ of the respondents agreed that Library 2.0 is about the implementatic new technologies such as blogs and wikis. The level of agreement was such that the remaining $6 \%$ accounted for by respondents who answered "not sure" to the question and no one explicitly disagr A graphical illustration of the data is shown in Figure 2.

Furthermore, another survey question asked respondents whether Library 2.0 was about improvement of virtual services. $86 \%$ agreed with this assertion, $2 \%$ disagreed and the remainder । either "neutral" or "not sure" responses. In addition to this, a triangulation of the "visibility" audit achieved by including a question in the web survey for respondents to confirm the services they either already implemented, planned to implement or those with no plans for implementation. It sh be said that there was a significant comparative consistency between the results of the "visibility a and the web survey. As with the audit, RSS was the most commonly implemented Web 2.0 service $40 \%$ of the respondents saying they had already implemented the service. As with the audit the sec most common Web 2.0 tool was found to be blogs (34\%). Similarly, the podcasts came third with of respondents confirming that these had been implemented in their libraries. 


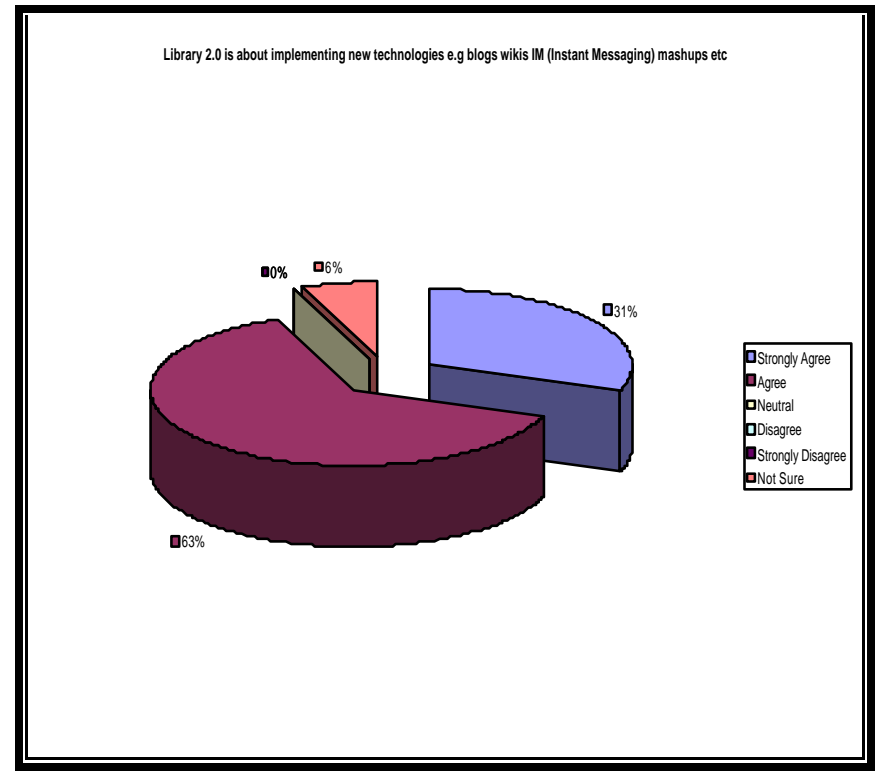

Figure 2. Chart showing the level of agreement to the assertion that Library 2.0 is about th implementation of new technologies

From discussions with the librarians during the interviews, it was found that Library 2.0 is being see the attempt to apply Web 2.0 applications and technologies within the library environment. Significa all the interviewees concurred that the main emphasis of Library 2.0 was to increase the Web pres $\epsilon$ of the library, and Web 2.0 technologies were being used as the platform to expedite this $g$ However, in three of the interviews, the suggestion was that there had not been much discussion a the term "Library 2.0" per se but instead an overall examination of the potential application of Web technology in the library environment. This was further emphasised in the notion that implementation of these Web 2.0 tools had not been as a direct response to a desire to be "Library If it turned out that this activity wasLibrary 2.0, then thiswas fine but this itself was not an objectiv the implementation. The interviewee who expressed most strongly this view proved to come from institution that had implemented several of the Web 2.0 technologies with great success. 
A combination of the findings of the audit and the web survey however showsthat there had not be great uptake of some services such as folksonomies, user tagging and social sites, even though th are the ones that epitomise Web 2.0. Interviewees were asked for their comment on this. The maj stated that there had not been a practical benefit that had been identified for the implementation of s services. It was suggested that services such as folksonomies were still being examined for applicability within the library environment, particularly in the context of issues of trust as has $b$ previously identified. ${ }^{11}$ By examining the findings of data collections "A", "B" and "C", it can thus suggested that Library 2.0 is the implementation and application of Web 2.0 technology within library environment. This matches the assertions made by Bradley ${ }^{9,}{ }^{10}$; Maness ${ }^{6}$ and Chad \& Miller

\section{Is Library 2.0 about the improvement of physical services?}

The literature eviewed in preparation for this study revealed that some argue that Library incorporates the improvement of physical services, without necessarily focusing on virtual service

web-based services. ${ }^{7,12}$ Responses to questions posed to data subjects on sets $B$ and $C$ provideı opportunity to explore this theme.

Forty-nine survey respondents considered this question. A summary of responses is shown in figu Of the 49 , a significant number appeared not to have any strong opinion as to whether Libran incorporated the improvement of physical services. Indeed, $44 \%$ of the study population in this ques chose to answer 'neutral'. The results revealed that $22 \%$ believed that Library 2.0 is about improvement of physical services and $30 \%$ did not. The interviews provided an opportunity to probe question further. 


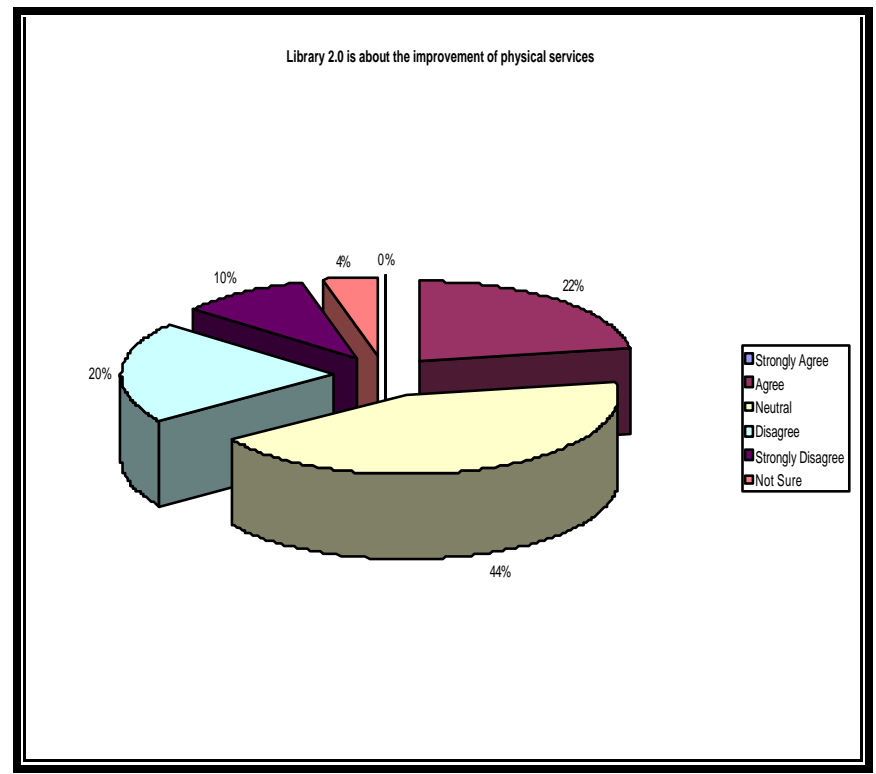

Figure 3. Level of agreement to the assertion that Library 2.0 is about the improvement of physical services

It was established during the interviews that the librarians did not view Library 2.0 to incorpc physical as well as virtual services. There was however a general consensus on the importance of physical component of LIS, with the librarians noting that users still valued the traditional serv offered over the counter and elsewhere within the physical building. Library 2.0 to them had, how been mainly focused on the improvement of web services. As explained by one interviewee, Librar is being seen as taking "small baby steps" towards improving the virtual presence of the library w to date had mainly been perceived as static. It was, however, interesting to note that two of interviewees acknowledged that their libraries had recently undertaken work of some phy renovations. One university had redesigned a whole floor of the library to be an open space that al collaborative and participative working between students. This physical setting would fit into Gordo definition of Library 2.0. However, the interviewee seemed not convinced that it had been done as 
of any plans to be Library 2.0. In addition, one of the interviewees noted that changes in virtual serv delivery often tended to fi Iter into the physical services.

The findings related to this research theme thus appear not to match the claims that Library incorporates the improvement of physical services. The main emphasis of Library 2.0 is implementation of web-based services. However, this is not to say that it is only about implementation of web-based services. Respondents to the web survey were asked about their lev agreement with the view that Library 2.0 is a combination of improving the library services, $k$ physical and virtual in participatory environment between users and librarians. The question rece 49 responses of which $70 \%$ agreed to the assertion as shown in Figure 4.

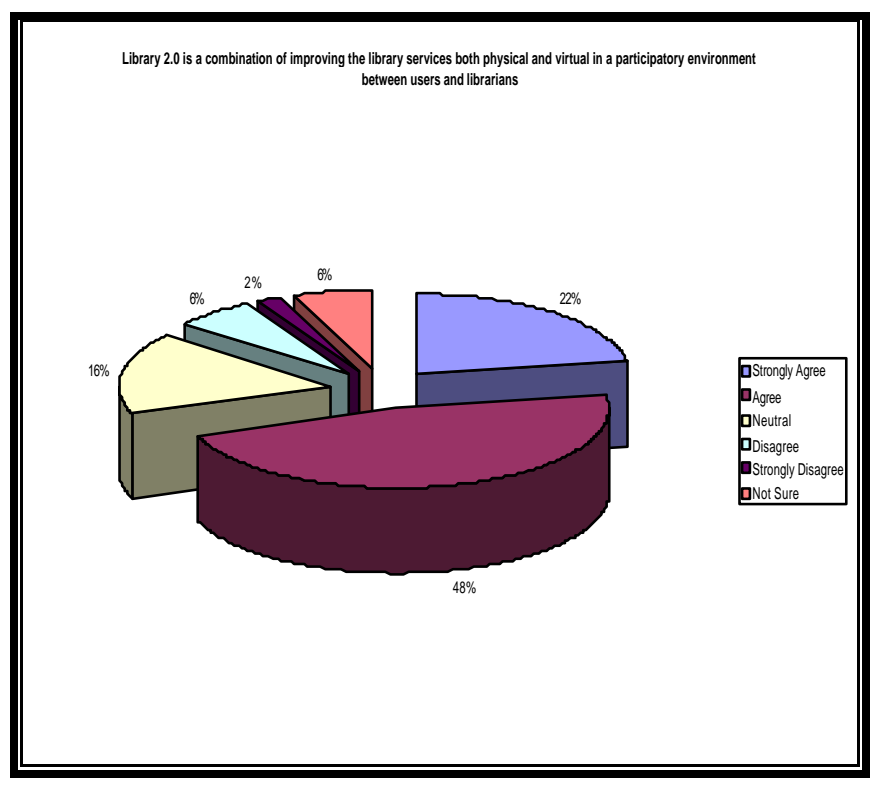

Figure 4. Library 2.0 is a combination of physical and virtual services 
Of particular interest is the interplay between physical services and Web 2.0 implementations desig to improve the experience of service delivery. This would include for example, podcasts as guided tc of library facilities as a response to student complaints about the difficulties of navigating buildings a lack of time available for subject librari ans to provide traditional induction tours. However, it should k said that this innovation, as with other developments such as the production of a library blog as a replacement for a traditional hard copy newsletter fit with the main tenet of academic library provisio that is, meeting users' information needs.

It has been established that Web 2.0 itself is technology driven, but the implementations within library are not being driven for the desire of just implementing the latest "gadgets" and "widgets" so it can be seen to be 2.0 compliant. Rather, the main focus has been to implement these Web $2.0 \mathrm{t}$ in the context of end-users' needs. Representatives of the universities that are already implemeI Web 2.0 toolsacknowledged that Library "1.0" services were still highly valued, and would probabl so for a long time. To this end, the assertions made by Maness ${ }^{6}$ resemble closely what is happenin the ground at the moment within UK HE academic libraries and being termed Library 2.0, In $s$ Library 2.0 refers the move towards virtual presence to meet user needs. Library 2.0 is also at improving physical services ${ }^{7}$ but for the moment, the main focus has been mainly on web-bi services. It is valid therefore that Library 2.0, whether being implemented from a virtual perspectiv physical perspective, is a realisation towards meeting user needs.

\section{To what extent is Library 2.0 something "new"?}

If Library 2.0 is the application of Web 2.0 technology to meet specific identified user needs the what extent is this something new? Libraries have a long history of adopting and implementing technology to meet user needs. ${ }^{6}$ Perhaps labelling these changes in services as Library $2 .($ inappropriate. 


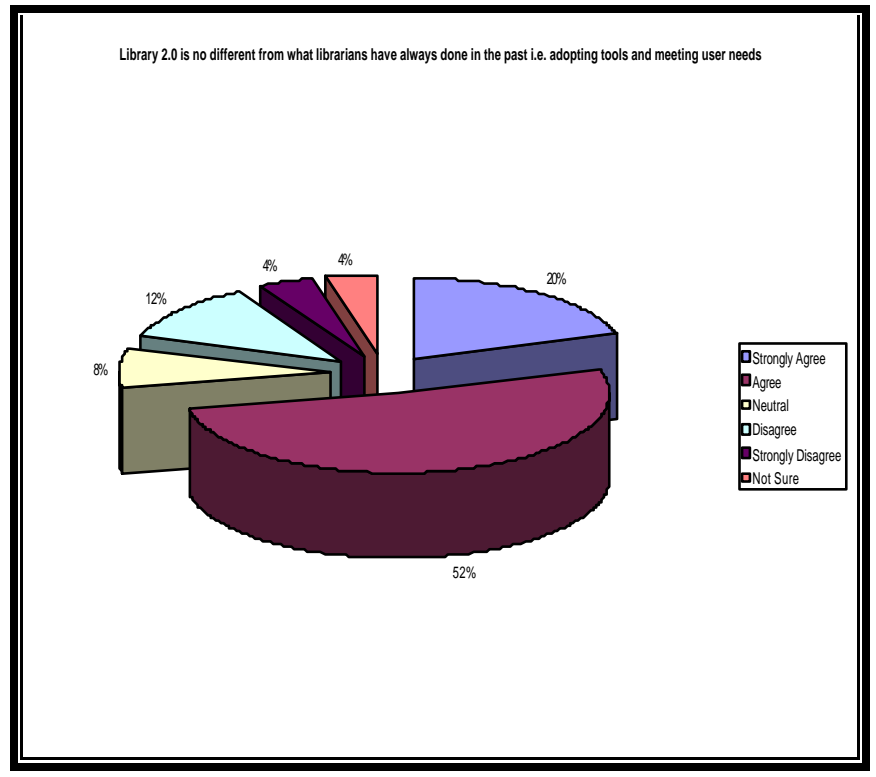

Figure 5. Responses assertion that Library 2.0 is not different

Figure 5 reveals that the majority of web survey respondents did not regard Library 2.0 as somet brand new. The interviewees were largely in agreement. However, a few fundamental differences । noted. These centre on the pace of change, which is now said to have greatly increased in light of ' 2.0 technology. Interviewees employed vocabulary such as "the culture of change", "embrac change", "enthusiasm" and "pace of change" in their discussion of this theme. Reference was mac the fact that previously users wanted a solution to the problem as it was defined in the pro requirements document and wanted it to work $100 \%$ of the time. In contrast, the current way of wor could give $90 \%$ of the requirements very quickly, may not work all the time and it was possible tha other $10 \%$ may never be completed. In six months the requirements may even have changed. $\mathrm{Cl}$ collaboration was required in project work, and acceptance that "perfect" solutions would not alway achieved, nor was always desired. This meant a change in work approach on the part of the lit staff. Another difference noted was that LIS often played catch-up with the commercial organisatior 
the past with respect of technology adoption. For once, LIS had been pushing hard to stay current other industry sectors in the context of Web 2.0 tools.

What has been the impact of Web/Library 2.0 on UK academic libraries?

A number of impacts of Web 2.0 and Library 2.0 were noted in the study. These relate to enthusiasm for librarians, engagement with users, the need for training and the relationship betw academics and students. Whilst it cannot be measured in percentages or monetary terms, Library 2 said to be creating a new enthusiasm within the library environment. This view was confirmed b interview participants. The argument is that previously librarians and libraries were perceived tc 'boring'. However, new terms are being used to describe the library experience ever since implementation of the Web 2.0 tools. For instance, at one institution, following the implementation o library tours podcast, students have been describing the service as "fantastic", "amazing", words r: associated with the library before. More podcasts have since been delivered. Similarly, at anc institution, it was suggested that "...Library 2.0 has given people a reason to be more daring in ideas of change". Library 2.0 makes people aware that they need to keep up with change and tha change is constant. That other information services are offering the new Web 2.0 tools makt increasingly difficult for librarians not to take notice.

It was also suggested from the interviews that Library 2.0 has made it possible to engage the use ways that have not be possible before, for example through podcasts. Interviewees were pleased statistics to show huge uptake of services provided by podcasts and blogs, and commented on these services' previous incarnations, for example as manuals, had in contrast been largely ignore users. A further impact of service delivery by Web 2.0 tools has been increased user-independence thus a reduction in needs for end-user training. Another observation relates to different communiti users in academic libraries. All interviewees noticed that while for example students had been gras the Web 2.0 tools such as wikis and podcasts with ease, academics have been lagging behind some even reluctant to try the services. A gap appears to have been created between the user-b: 
served by academic libraries. There was concern that two types of service delivery would need ts supported in the future, one for those "born with the chip" and one for the older generation.

\section{Conclusion}

This study reveals that in the UK, academic librarians have taken Library 2.0 to be the applicatio Web 2.0 tools and techniques within the library environment with user services at the heart of implementation. Not every Web 2.0 technology has been embraced: RSS, blogs and podcasts are most popular to date. Thus Library 2.0 is about selectively choosing from a set of tools which happ be Web 2.0, without any compulsion on the part of the library service to be Library 2.0. The perspe that Library 2.0 incorporates the physical services has not been widely substantiated. However, Web 2.0 applications implementation tends to impact the way in which physical services are deliver It is emphasised in these research results that librarians do not perceive Library 2.0 to be presenti new paradigm. Although reacting to the pace of change and willingness to adapt to change have $k$ identified as having an impact, the underlying principle of meeting users' needs - one which has । embedded in the long history of librarians adopting technology is still the basic tenet of library information services provision.

The most significant impacts in this context of the move to adopting these tools are being felt in sel ways related to how librarians and the relationship between academic libraries and their users perceived, not least in servicing the needs of different generations of users.

\section{Acknowledgements}

Survey participants and anonymous interviewees 
1. O'Reilly, T. (2005a, September 30). What is Web 2.0: Design Patterns and Business Mode the Next Generation of Software. Retrieved November 18, 2007, http://www.oreillynet.com/pub/a/oreilly/tim/news/2005/09/30/what-isweb-20.html

2. BBC News Online. (2006a, May 24). Social sites wrestle for top spot. Retrieved Novemb 2007, from http://news.bbc.co.uk/1/hi/technology/5012194.stm

3. BBC News Online. (2006b, December 18). Social networks top Google search. Retr November 18, 2007, from http://news.bbc.co.uk/1/hi/technology/6189809.stm

4. Chad, K, \& Miller, P. (2005, November). Do libraries matter? The rise of Library 2.0. Retr November 18 , 2007 , http://www.talis.com/applications/downloads/white papers/DoLibrariesMatter.pdf

5. Miller, P. (2006, February). Library 2.0: the challenge of disruptive innovation. Ret November 18, 2007, from http://www.talis.com/resources/documents/447_Library_2_prf1.p

6. Maness, J.M. (2006, June). Library 2.0 Theory: Web 2.0 and Its implications for Libre Webology 3(2). Retrieved November 18, 2007 from http://www.webology.ir/2006/v3n2/a25.h

7. Casey, M. E., \& Savastinuk, L. C. (2006, September 1). Library 2.0: service for the generation library. Library Journal, 131(14), 40-42. Retrieved October 20, 2006, from EBSC( Database.

8. Crawford, W. (2006, Midwinter). Library 2.0 and "Library 2.0". Cites \& hsights, 6(2), Retrieved November 18, 2007, from http://citesandinsights.info/civ6i2.pdf

9. Bradley, P. (2006a, May). Web 2.0: a new generation of services. Library \& Information Uk 5(5), 32-33.

10. Bradley, P. (2006b, June). Web 2.0: a new generation of services Part 2. Library \& Informati Update, 5(6), 38-39.

11. Harris, C. (2006, November). A matter of (radical) trust. School Library Journal, 52(11), 5 Retrieved December 14, 2006, from EBSCOhost Database.

12. Gordon, R, S. (2006). What will you do today?. Library Journal (131)17, 43. Retrieved Dece 28, 2006, from EBSCO Host Databases 